\title{
The changing nature of chronic care and coproduction of care between primary care professionals and patients with COPD and their informal caregivers
}

\author{
This article was published in the following Dove Press journal: \\ International Journal of COPD \\ 27 January 2016 \\ Number of times this article has been viewed
}

\section{Jane Murray Cramm \\ Anna Petra Nieboer}

Department of Health Policy and Management (iBMG), Erasmus University Rotterdam, Rotterdam, the Netherlands
Correspondence: Jane Murray Cramm Erasmus University (iBMG), Burgemeester Oudlaan 50, 3062 PA Rotterdam, the Netherlands $\mathrm{Tel}+31104089701$

Fax +3I 104089094

Email cramm@bmg.eur.nl
Abstract: The aim of this study was to investigate whether care delivery in accordance with a care model is associated with co-productive relationships between professionals and COPD patients and their informal caregivers. A co-productive relationship refers to productive patient-professional interaction or shared decision making. This cross-sectional study was conducted in 2014 among 411 patients (out of 981) enrolled in the Dutch COPD care program Kennemer Lucht and 62 professionals treating them (out of 97). Kennemer Lucht COPD involved multicomponent interventions within all six dimensions of the chronic care model (organizational support, community, self-management, decision support, delivery system design, and information and communications technology) to improve the quality of care for patients with COPD. This approach was expected to improve relational coproduction of care between professionals and patients with COPD and their informal caregivers. Results show clearly that the perceived quality of chronic care delivery is related significantly to productive interaction/ relational coproduction of care. The strength of the relationship between perceptions of quality of chronic care and relational coproduction among patients is strong $(r=0.5 ; P \leq 0.001)$ and among professionals moderate $(r=0.4 ; P \leq 0.001$ relational coproduction with patients and informal caregivers). Furthermore, patients' perceptions of the quality of chronic care were associated with the existence of productive interaction with health care professionals $(\beta=0.7$; $P \leq 0.001)$. The changing nature of chronic care is associated with coproduction of care, leading to the development of more productive relationships between primary care professionals and COPD patients and their informal caregivers. Further research is necessary to determine how best to sustain these developments.

Keywords: chronic disease, disease management, interaction, patient-centered care, quality of care, relational coproduction, relational coordination

\section{Background}

COPD is a chronic condition known to cause death and disability worldwide. ${ }^{1}$ Around the world, health care systems are struggling with finding the best way to deal with large numbers of chronically ill patients while keeping costs low and quality high. ${ }^{2}$ Increasing evidence suggests that COPD patients would benefit from an integrated primary care approach tailored to their individual chronic needs. ${ }^{3,4}$

The chronic care model (CCM) is an innovative integrated primary care approach that can be used to support these growing patient-professional interdependencies, thereby promoting coproduction of care with COPD patients in the primary care setting. ${ }^{5-11}$ The CCM guides the transition from the reactive provision of acute care 
to the proactive delivery of chronic care in an organized, structured, and planned manner. The assembly of effective multidisciplinary teams of professionals whose interaction with chronically ill patients and informal caregivers is planned can aid this transition. ${ }^{2}$ The CCM aims to promote a more complete understanding of patients' lives and preferences, the customization of high-quality care, and the empowerment of patients as proactive participants who take responsibility in their care delivery. ${ }^{12,13}$ These goals are encompassed in the term "patient-centered care". ${ }^{11}$

To support the chronic needs and improve well-being of COPD patients in the primary care setting, we need integrated and proactive care aimed to improve productive interactions between COPD patients, their informal caregivers, and professionals treating them. This means that patients and informal caregivers need to be proactive and well informed. In order to do so, they need to be provided with sufficient information, supported to make wise decisions and become strong self-managers by sharing relevant information concerning their disease and asking for the right support in managing their illness. In addition to the changing roles of patients and informal caregivers, professionals' roles also need to change to improve outcomes for COPD patients in the primary care setting. Professionals with different occupational backgrounds treating COPD patients (eg, general practitioner, pharmacist, nurse, dietician, physical therapist) are expected to coordinate and integrate their care to coproduce care delivery with COPD patients and their informal caregivers and thereby improve outcomes.

Care delivery used to take a more paternalistic form with professionals making most decisions themselves and patients taking a more reactive passive role rather than making shared decisions and coproducing care delivery together as equals. ${ }^{14}$ Nowadays, evidence shows that patient-centered care is needed to improve organizational as well as patient outcomes via coproduction of care between patients, informal caregivers, and professionals. ${ }^{14,15}$ Research, however, has shown that many patients do not feel they are equal partners when it comes to coproduction of care with professionals. ${ }^{16}$ One of the difficulties identified as a barrier in the establishment of a productive patient-professional interaction is having the capabilities, such as taking a more assertive role and possessing the right communication skills needed for such interactions, ${ }^{17-20}$ which not all COPD patients have. Chronically ill patients, especially those with low educational levels, may find these objectives particularly difficult to achieve. ${ }^{21-23}$ Earlier research, for example, showed that chronically ill patients with higher educational levels receive better care compared to those with lower educational levels.
This discrepancy in the quality of primary care delivery may be caused by differences in the behavior of professionals (eg, the ability to explain things clearly) toward lower and higher educated chronically ill patients as well as potential differences in their needs and demands. ${ }^{24}$ The successful establishment of creating productive patient-professional interaction is therefore expected to vary according to the educational levels of patients and informal caregivers. Patients with COPD are known to have lower educational levels compared to the general population as well as other chronically ill populations (eg, those with diabetes, cardiovascular conditions); ${ }^{23}$ thus, improvement of high-quality care and establishment of coproduction of care with these patients is especially relevant. Furthermore, preferences in the coproduction of care delivery are known to vary among patients and informal caregivers. Given the growing patientprofessional interdependency, professionals should be more creative and sensitive to personal needs, ${ }^{25}$ which calls for a patient-centered approach with patients and professionals taking an equal role. ${ }^{26}$ Decisions need to be made based on personal preferences, needs, and circumstances of each patient and their informal caregiver. ${ }^{14}$ Therefore, professionals are expected to regularly ask about patients' lives and their current (especially changed) situation, which is expected to stimulate a productive patient-professional interaction.

Shared decision making or stimulating productive collaboration between professionals, COPD patients, and their informal caregivers may be achieved via frequent, accurate, and timely communication combined with a relationship characterized by mutual respect, shared goals, and shared knowledge. Gittell identified this concept as relational coordination (among professionals) or relational coproduction (among patients, informal caregivers, and professionals). ${ }^{27-29}$ Rather than a situation in which health care professionals tell patients what they must do or which treatment they should receive, relational coordination and/or relational coproduction of care refers to productive interaction characterized by increasing interdependencies between health care professionals and patients regarding what needs to be done (goal setting) and how best to do it (treatment choices). ${ }^{22}$ Although "evidence-based medicine" and "patient-centered medicine" are often identified as being two separate paradigms, some successful innovative health care solutions, such as disease management programs in primary care settings, bring these separate worlds together. ${ }^{11}$ Respecting and responding to patient preferences - which is the hallmark of patientcentered care - means eliciting, exploring, and questioning preferences based on evidence-based medicine and then helping patients construct their preferences. ${ }^{21}$ As such, 
true patient-centered care requires shared deliberation and coproduction of care that goes beyond the provision of information based on available evidence - families can also provide essential input showing interdependence not only between professionals and patients but also with informal caregivers.

Productive patient-professional interactions are characterized by high levels of shared goals, shared knowledge, and mutual respect that together foster attentiveness to the situation and to one another whereas poor patient-professional interactions are expected to harm the quality of care delivery and patient outcomes. ${ }^{21,22,29}$ Although health care decisions are broadly accepted to require the integration of research-based evidence and individual preferences, the implementation of such approaches remains limited in practice. As contexts involving chronically ill patients have been identified as most appropriate for shared decision making or coproduction of care, this situation represents a missed opportunity. Although interest in productive patient-professional interaction or coproduction of care is growing, this area of research is still quite new and mainly consists of conceptual literature or qualitative research. ${ }^{30}$ To learn more theoretically, however, we must know much more empirically. Empirical investigations of high-quality chronic care and its relationships to productive patient- and caregiver-professional interactions are scarce. This study thus aimed to investigate whether highquality care delivery in the primary care setting is associated with co-productive relationships between professionals and patients with COPD and their informal caregivers.

\section{Methods}

\section{Setting}

This cross-sectional study was conducted in April and May 2014 among patients enrolled in the Dutch COPD care program Kennemer Lucht and professionals treating them. ${ }^{31-33}$ This disease management program, initiated in March 2012, involved multicomponent interventions within all six dimensions of the CCM (organizational support, community, self-management, decision support, delivery system design, and information and communications technology [ICT]) to improve the quality of care for patients with COPD (Table 1 for a full overview of the 35 implemented interventions). ${ }^{33}$ This approach was expected to improve relational coproduction of care between professionals and patients with COPD and their informal caregivers.

\section{Participants and study design}

The Kennemer Lucht program included all patients diagnosed with COPD. No additional inclusion criterion was
Table I Interventions implemented in the disease management program according to the six dimensions of the chronic care model

Kennemer Lucht COPD management program

Organizational support Integrated financing

Organizational support Sustainable financing agreements with health

insurers

Community insurers

Community

Cooperation with external community partners

\section{Community}

Community

Community

Self-management

Self-management

Self-management

Self-management

Self-management

Self-management

Self-management

Decision support

Decision support

Decision support

Decision support

Decision support

Decision support

Decision support

Decision support

Decision support

Decision support

Delivery system design

Delivery system design

Delivery system design

Delivery system design

Delivery system design

ICT

ICT

ICT

ICT

ICT

ICT

Multidisciplinary and transmural collaboration

Role model in the area

Regional collaboration for spread of the DMP

Regional training course

Promotion of disease-specific information Individual care plan

Lifestyle interventions (physical activity, diet, quit smoking)

Personal coaching

Motivational interviewing

Informational meetings

Diagnosis and treatment of mental health issues

Care standards/clinical guidelines

Uniform treatment protocol in outpatient and inpatient care

Training and independence of practice assistants

Professional education and training for care providers

Automatic measurement of process/ outcome indicators

Audit and feedback

Periodic evaluation of interventions and goal achievement

Structural participation in knowledge exchange

Quality of Life questionnaire

Measurement of patient satisfaction

Delegation of care from specialist to nurse/ care practitioner

Systematic follow-up of patients

Meeting of different disciplines to exchange information

Monitoring of high-risk patients

Periodic discussions between professionals (and patients)

Electronic Patient Records system (without Patient Portal)

Integrated Chain Information System

Use of ICT for internal and/or regional benchmarking

Creation of a safe environment for data exchange

Systematic registration by every caregiver

Exchange of information among care

disciplines

Notes: Copyright @2015. Reproduced from Cramm JM, Jolani S, van Buuren S, Nieboer AP. Better experiences with quality of care predict well-being of patients with chronic obstructive pulmonary disease in the Netherlands. Int J Integr Care. 2015;15:e28. ${ }^{33}$

Abbreviations: DMP, disease management program; ICT, information and communications technology. 
applied. Patients received questionnaires at home via mail. Three to four weeks later, reminder notices were sent to non-respondents. This approach led to a response rate of $42 \%$ (411 patients responded out of a total of 981 who were invited to participate). The same strategy was applied to assess professionals' experiences with care delivery, which resulted in a $64 \%$ response rate (62 out of 97 professionals responded). The ethics committee of the Erasmus University Medical Center of Rotterdam approved this study in April 2012 (MEC-2012-143). Participants did not provide written informed consent, however, the study included only those patients who agreed to participate.

\section{Survey measures}

\section{Patients' perceptions of care quality}

Patients were asked to complete the 20-item Patient Assessment of Chronic Illness Care questionnaire, which uses a five-point response scale ranging from "almost never" to "almost always". ${ }^{34}$ Examples of items are: "When I received care for my chronic illness over the past 6 months, I was [...] asked for my ideas when we made a treatment plan”, “[ ...] satisfied that my care was well organized", "[...] asked how my chronic illness affects my life", and "[...] asked how my visits with other doctors were going". Scores range from 1 to 5 , with higher scores representing higher-quality chronic care delivery. Cronbach's alpha of the relational coproduction instrument was 0.95 indicating excellent reliability.

\section{Professionals' perceptions of care quality}

Professionals were asked to complete the Assessment of Chronic Illness Care, Short version (ACIC-S). ${ }^{35}$ The ACIC-S consists of 21 items covering the six dimensions of the CCM: health care organization, community linkages, self-management support, delivery system design, decision support, and clinical information systems $(n=3$ each). The three remaining items integrate the six components, such as by linking patients' self-management goals to information systems. Responses to ACIC-S items (eg, "evidence-based guidelines are available and supported by provider education") fall within four descriptive levels of implementation ranging from "little or none" to "fully implemented intervention". Respondents were asked to choose the degree to which each description applied within each of the four levels on a scale of $0-11$. The result is a total mean score ranging from $0-11$, with categories defined as 0-2 (little or no support for chronic illness care), 3-5 (basic or intermediate support), 6-8 (advanced support), and 9-11 (optimal or comprehensive integrated care for chronic illness). ${ }^{36}$ Subscale scores for CCM dimensions were derived by calculating an average score for all items in each subsection when responses to at least two of three items were available. Total scale scores were calculated by averaging subscale scores when responses in at least four of seven subsections were available. Cronbach's alpha of the ACIC-S was 0.92 indicating excellent reliability.

\section{Patients' perceptions of relational coproduction with professionals}

We used the relational coordination instrument (seven items rated on a five-point scale) to elicit patients' perceptions of the productivity of interactions (characterized as coproduction of care) with general practitioners, practice nurses, dieticians, physical therapists, medical specialists, and nurses. The instrument contained four items assessing the quality of communication with health care professionals (frequent, accurate, timely, and problem-solving communication) and three items concerning relationship dimensions (shared goals, mutual respect, and knowing each other's role in the process). This relational coordination instrument was originally developed for the airline industry ${ }^{37}$ and has also been used in hospitals, ${ }^{38,39}$ primary care,,${ }^{6,7}$ and community care ${ }^{40}$ settings among professionals and in disease management programs in the primary care setting among chronically ill patients. ${ }^{21,22}$ Cronbach's alpha of the relational coproduction instrument was 0.94 indicating excellent reliability.

\section{Professionals' perceptions of relational coproduction with patients and informal caregivers}

Professionals were asked the same seven questions to assess their perceptions of the productivity of interactions (characterized as coproduction of care) with patients with COPD and their informal caregivers..$^{6,77-40}$ Cronbach's alpha of the relational coproduction instrument was 0.94 indicating excellent reliability.

\section{Background characteristics}

We additionally asked for background characteristics of participants (eg, age, sex, marital status, educational level). Patients' educational levels were characterized using six levels ranging from 1 (no school or primary education [ $\leq 7$ years]) to 6 (university degree $[\geq 18$ years]). We dichotomized this item into "high" (more than primary education) educational levels and "low" (no school or primary education). Patients' marital status was dichotomized into "single" (single, divorced, or widowed) or "married" (married or living together in a long-lasting relationship). We additionally asked for professionals' occupation, number of years working in the current organization, and number of working hours per week. 


\section{Statistical analyses}

We used descriptive statistics to characterize patients' and professionals' perceptions of the quality of care provided within the Kennemer Lucht program and the relational coproduction of care. Correlation analyses (Pearson) were used to assess the relationship between chronic care quality and the establishment of relational coproduction, based on professionals' and patients' survey responses. Significant findings will lead us to drop the null hypothesis of a nonexisting relationship between the independent and dependent variables. Given the small number of surveys filled in by professionals, multilevel regression analyses were conducted using only patients' survey responses. To account for the nested structure of the study population (patients [level 1] nested in health care practices [level 2]), we employed a linear multilevel random-effects model to investigate the predictive roles of chronic care quality in relational coproduction while controlling for patients' age, sex, educational level, and marital status. Two-sided $P$-values $\leq 0.05$ were considered to be significant. Analyses were performed using SPSS software (version 21; IBM Corporation, Armonk, NY, USA).

\section{Results}

Table 2 displays the baseline characteristics of patients with COPD. Of the 411 respondents, $44 \%$ were female, $36 \%$ had low educational levels, and $32 \%$ were single.

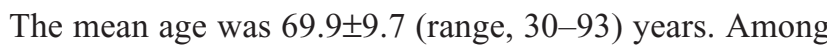
patients, the mean perceived quality of chronic care score was $2.8 \pm 0.9$ and the mean rating of relational coproduction was $3.6 \pm 1.1$.

Table 2 Descriptive statistics for 44 I patients participating in the Kennemer Lucht COPD management program

\begin{tabular}{lll}
\hline Descriptive statistics & $\begin{array}{l}\text { Mean } \pm \text { SD } \\
\text { or percentage }\end{array}$ & Range \\
\hline Age (years) & $69.9 \pm 9.7$ & (actual range 30-93) \\
Sex (female) & 44 & \\
Marital status (single) & 32 & \\
Educational level (low) & 36 & \\
Perceived quality of chronic care & $2.8 \pm 0.9$ & $\mathrm{I}-5$ \\
Relational coproduction with & $3.6 \pm \mathrm{I} . \mathrm{I}$ & $\mathrm{I}-5$ \\
professionals & & \\
$\quad$ Frequent communication & $3 . \mathrm{I} \pm \mathrm{I} . \mathrm{I}$ & $\mathrm{I}-5$ \\
$\quad$ Timely communication & $3.2 \pm \mathrm{I} .3$ & $\mathrm{I}-5$ \\
$\quad$ Accurate communication & $3.5 \pm \mathrm{I} .3$ & $\mathrm{I}-5$ \\
$\quad$ Problem-solving communication & $3.9 \pm \mathrm{I} .2$ & $\mathrm{I}-5$ \\
$\quad$ Shared knowledge & $3.8 \pm \mathrm{I} .2$ & $\mathrm{I}-5$ \\
$\quad$ Shared respect & $4.3 \pm \mathrm{I} .0$ & $\mathrm{I}-5$ \\
Shared knowledge goals & $3.9 \pm \mathrm{I} .2$ & $\mathrm{I}-5$ \\
\hline
\end{tabular}

Abbreviation: SD, standard deviation.
Table 3 Relational coproduction between patients and professionals within the Kennemer Lucht COPD management program

\begin{tabular}{lll}
\hline $\begin{array}{l}\text { Patients' perceptions of relational } \\
\text { coproduction with }\end{array}$ & Mean \pm SD & Range \\
\hline General practitioner & $3.8 \pm \mathrm{I} .0$ & $\mathrm{I}-5$ \\
Specialist & $2.9 \pm \mathrm{I} .5$ & $\mathrm{I}-5$ \\
Nurse practitioner & $3.7 \pm \mathrm{I} .2$ & $\mathrm{I}-5$ \\
Dietician & $\mathrm{I} .7 \pm \mathrm{I} .3$ & $\mathrm{I}-5$ \\
Physical therapist & $2.4 \pm \mathrm{I} .5$ & $\mathrm{I}-5$ \\
\hline
\end{tabular}

Abbreviation: SD, standard deviation.

Table 3 displays patients' perceptions of relational coproduction with professionals. We found the highest degrees of relational coproduction with general practitioners (mean, 3.8) and nurse practitioners (mean, 3.7).

Of the professionals, $64 \%$ were female, $84 \%$ work for at least 22 hours per week, and $97 \%$ have been working in the organization for at least 3 years. Looking at their occupation $59 \%$ of the respondents are general practitioners, $39 \%$ practice nurses, and $2 \%$ physician assistants. Professionals' mean ratings of overall relational coproduction with patients and informal caregivers were $4.2 \pm 0.4$ and $3.3 \pm 0.8$, respectively (Table 4). Scores for the extent to which professionals felt that they delivered integrated care, according to CCM dimensions, ranged from 6.9 for self-management to 8.6 for delivery system design. The overall mean score for all dimensions was 7.6, indicating advanced support for chronic illness care within the Kennemer Lucht program.

Associations between the perceived quality of chronic care and productive interaction between patients and care providers are displayed in Tables 5 (professionals' perceptions) and 6 (patients' perceptions). These results show that the perceived quality of chronic care delivery is related significantly to productive interaction/relational coproduction of care. The strength of the relationship between

Table 4 Descriptive statistics for 62 professionals working in the Kennemer Lucht disease management program

\begin{tabular}{lll}
\hline Descriptive statistics & Mean \pm SD & Range \\
\hline Overall perceived quality of chronic care & $7.6 \pm 1.4$ & $0-1 \mathrm{I}$ \\
$\quad$ Organizational support & $8.1 \pm 2.1$ & $0-1 \mathrm{I}$ \\
Community & $7.4 \pm 2.0$ & $0-1 \mathrm{I}$ \\
Self-management & $6.9 \pm 1.8$ & $0-1 \mathrm{I}$ \\
Decision support & $7.6 \pm 1.5$ & $0-1 \mathrm{I}$ \\
Delivery system design & $8.6 \pm 1.5$ & $0-1 \mathrm{I}$ \\
ICT & $7.2 \pm I .7$ & $0-1 \mathrm{I}$ \\
Perceived productive interaction with & $4.2 \pm 0.4$ & $\mathrm{I}-5$ \\
patients with COPD & & \\
Perceived productive interaction with & $3.3 \pm 0.8$ & $\mathrm{I}-5$ \\
informal caregivers of patients with COPD & & \\
\hline
\end{tabular}

Abbreviations: SD, standard deviation; ICT, information and communications technology. 
Table 5 Correlations between quality of chronic care and relational coproduction among professionals $(n=62)$

\begin{tabular}{|c|c|c|}
\hline $\begin{array}{l}\text { Quality of chronic } \\
\text { care }\end{array}$ & $\begin{array}{l}\text { Relational } \\
\text { coproduction with } \\
\text { patients with COPD }\end{array}$ & $\begin{array}{l}\text { Relational } \\
\text { coproduction with } \\
\text { informal caregivers }\end{array}$ \\
\hline $\begin{array}{l}\text { Overall perceived } \\
\text { quality of chronic care }\end{array}$ & $0.4 * * *$ & $0.4 * * *$ \\
\hline $\begin{array}{l}\text { Organizational } \\
\text { support }\end{array}$ & $0.3 *$ & -0.0 \\
\hline Community & $0.3^{*}$ & 0.2 \\
\hline Self-management & $0.3^{* *}$ & $0.5^{* * *}$ \\
\hline Decision support & $0.4 * *$ & $0.4^{* *}$ \\
\hline $\begin{array}{l}\text { Delivery system } \\
\text { design }\end{array}$ & $0.4^{* * *}$ & $0.4^{* *}$ \\
\hline $\mathrm{ICT}$ & 0.2 & 0.4 \\
\hline
\end{tabular}

Notes: $* * * P \leq 0.001, * * P \leq 0.01, * P \leq 0.05$.

Abbreviation: ICT, information and communications technology.

perceptions of quality of chronic and relational coproduction among patients is strong ( $r=0.5$; Table 6$)$ and among professionals moderate ( $r=0.4$ relational coproduction with patients and informal caregivers; Table 5).

The results of multilevel analyses show that patients' perceptions of the quality of chronic care predicted the existence of productive interaction with health care professionals ( $\beta=0.7 ; P \leq 0.001$; Table 7$)$. Meaning that one extra unit of perceived quality of care among patients leads to an improvement of 0.7 regarding productive patient-professional interaction.

\section{Discussion}

This study aimed to investigate whether the perceived quality of care delivery in the primary care setting is associated with co-productive relationships between professionals and patients with COPD and their informal caregivers. In line with previous findings among chronically ill patients, ${ }^{21}$ this study showed that the implementation of a constellation of interventions falling within all six CCM dimensions leads to relational coproduction of care, as perceived by patients. This study adds to this knowledge by showing that health care professionals also feel that quality of chronic illness care improves relational coproduction with patients and their informal caregivers.

Table 6 Correlations among background characteristics, perceived quality of chronic care, and relational coproduction among patients $(n=4 I I)$

\begin{tabular}{ll}
\hline $\begin{array}{l}\text { Background characteristics and } \\
\text { quality of chronic care }\end{array}$ & Relational coproduction \\
\hline Age (years) & -0.1 \\
Marital status (single) & 0.0 \\
Low educational level & 0.0 \\
Sex (female) & 0.1 \\
Perceived quality of chronic care & $0.5^{* * *}$ \\
\hline
\end{tabular}

Note: ${ }^{* * * P} \leq 0.001$.
Table 7 Predictors of relational coproduction among patients, determined by multilevel regression analyses (random intercepts model; $\mathrm{n}=344$ )

\begin{tabular}{lll}
\hline $\begin{array}{l}\text { Predictors of relational } \\
\text { co-production }\end{array}$ & $\beta$ & SE \\
\hline Constant & $1.6^{* * *}$ & 0.4 \\
Age (years) & 0.0 & 0.0 \\
Marital status (single) & 0.0 & 0.1 \\
Low educational level & -0.0 & 0.1 \\
Sex (female) & 0.1 & 0.1 \\
Perceived quality of chronic care & $0.7^{* * *}$ & 0.1 \\
\hline
\end{tabular}

Notes: $* * * P \leq 0.001$ (two-tailed). List-wise deletion of missing cases. Abbreviation: SE, standard error.

We found that patients perceived greater degrees of relational coproduction with general practitioners and nurse practitioners than with physical therapists and dieticians. This finding may be explained by the permanent nature of relationships between chronically ill patients and general practitioners and nurse practitioners, in contrast to typically fixed contact with physical therapists and dieticians. Increased familiarity with one another and a history of working together thus lead to higher levels of relational coproduction. Previous research has shown that longitudinal relationships between patients and physicians (continuity of care) positively affect outcomes. . $^{41,42}$

Even though previous research among patients with various chronic diseases (eg, cardiovascular disease, diabetes, COPD) showed that less-educated patients perceived less productive interaction, ${ }^{21}$ we found that educational level was related significantly to coproduction of care among patients with COPD in the present study. Such a relationship is less likely to be detected among patients with COPD, who typically have lower educational levels. However, professionals working with these patients may have developed more skills and accumulated more experience with less-educated patients.

The limitations of this study include its cross-sectional nature, which allowed us to identify associations but not to determine causality. Second, this study included patients with COPD and professionals participating in a single disease management program in the Netherlands. Our findings may not be generalizable to COPD management programs in other countries. Finally, non-response bias, especially with regard to patients ( $42 \%$ response rate), may have affected the results. Our response rate, however, is similar to those achieved in other studies involving mail-based questionnaires. ${ }^{43}$

Even though the positive impacts of relational coordination among professionals on operational outcomes such as quality, safety, efficiency, and financial outcomes are widely supported, only a handful of studies have explored the impact of relational coordination (also known as relational 
coproduction) between professionals and patients and/or informal caregivers. Building on available evidence, we provide new evidence in the arena of relational coordination theory and offer hypotheses for further exploration. Relational coordination among professionals is theoretically strengthened or weakened by the design of organizational structures. The present study additionally showed that use of a disease management program with a patient-centered approach implementing interventions within all six dimensions of the CCM is related to relational coproduction of care between professionals and patients and their informal caregivers. This finding implies that the quality of communication and collaboration between informed, pro-actively engaged patients with COPD and organized, trained, and equipped health care teams depends on the organizational structure, in this case the perceived quality of care delivery. Relational coproduction requires consistent patient-centered support, with an emphasis on empowering patients to be proactive and to participate in care delivery. ${ }^{11,21,22}$ The stimulation of productive interaction and active participation among informed patients with COPD may be achieved by self-management interventions, such as the provision of disease-specific information (eg, via informational meetings with patients and their informal caregivers), goal setting (via motivational interviewing and personal coaching), and the development of action plans (via individual care plans). The creation of organized, trained, and equipped health care teams, in turn, may result from decision support interventions (eg, use of care standards, clinical guidelines, treatment protocols, education, training, regular measurement of process and outcome indicators, auditing/feedback, periodic evaluation of interventions, and goal achievement), delivery system design interventions (eg, systematic follow-up of patients, meetings between professionals from different disciplines to exchange information, periodic discussions between professionals [and patients]), and ICT interventions (eg, use of electronic patient records systems, integrated chain information systems, ICT for internal and/or regional benchmarking, exchange of information among care disciplines). The development of effective collaboration is complex, difficult, and time consuming, and it often consumes scarce resources. ${ }^{28}$ The effectiveness of various collaboration forms supportive of the changing interdependencies among professionals, patients, and informal caregivers, in terms of experiences and outcomes, and the conditions under which they succeed, requires further research. Consistent with relational coordination theory, we found empirical evidence for the positive association between care quality and relational coproduction of care. Relational coordination involves communication among interdependent professionals and linking of their roles for the purpose of task integration. The findings of the current study extends relational coordination theory by showing that relational coordination, task interdependencies, and the influences of organizational structures also apply to relational coproduction of care among professionals, patients, and informal caregivers, pointing to the universal applicability of these mechanisms. The serious gaps in understanding and improving the development and sustainment of coproduction of care among chronically ill patients lend urgency to the examination of various patient-centered solutions and understanding of their measurement and effectiveness in various settings. Our findings hint that the changing nature of chronic care affects coproduction of care, leading to the development of more productive relationships between primary care professionals and patients with COPD and their informal caregivers. Further research is necessary to determine how best to sustain these developments.

\section{Acknowledgment}

This study was funded by Boehringer Ingelheim BV. The views expressed are those of the authors.

\section{Disclosure}

The authors report no conflicts of interest in this work.

\section{References}

1. World Health Organization. The global strategy on diet, physical activity and health. Geneva: World Health Organization; 2008. Available from: http://www.who.int/dietphysicalactivity/strategy/eb11344/ strategy_english_web.pdf. Accessed November 15, 2015.

2. Wagner EH, Austin BT, Davis C, Hindmarsh M, Schaefer J, Bonomi A. Improving chronic illness care: translating evidence into action. Health Aff (Millwood). 2001;20(6):64-78.

3. Lenfant C. Shattuck lecture - clinical research to clinical practice - lost in translation? N Engl J Med. 2003;349(9):868-874.

4. Bodenheimer T, Wagner $\mathrm{EH}$, Grumbach $\mathrm{K}$. Improving primary care for patients with chronic illness. The chronic care model, part 2. JAMA. 2002;288(15):1909-1914.

5. Coleman K, Austin BT, Brach C, Wagner EH. Evidence on the chronic care model in the new millennium. Health Aff (Millwood). 2009;28(1): $75-85$.

6. Cramm JM, Nieboer AP. Relational coordination promotes quality of chronic-care delivery in Dutch disease-management programs. Health Care Manage Rev. 2012;37(4):301-309.

7. Cramm JM, Nieboer AP. In the Netherlands, rich interaction among professionals conducting disease management led to better chronic care. Health Aff (Millwood). 2012;31(11):2493-2500.

8. Tsai AC, Morton SC, Mangione CM, Keeler EB. A meta-analysis of interventions to improve care for chronic illnesses. Am J Manag Care. 2005 11(8):478-488.

9. Wagner EH, Austin BT, Von Korff M. Organizing care for patients with chronic illness. Milbank Q. 1996;74(4):511-544.

10. Wagner EH, Austin BT, Von Korff M. Improving outcomes in chronic illness. Manag Care Q. 1996;4(2):12-25.

11. Wagner EH, Bennett SM, Austin BT, Greene SM, Schaefer JK, Von Korff M. Finding common ground: patient-centeredness and evidence-based chronic illness care. J Altern Complement Med. 2005;11 Suppl 1:S7-S15. 
12. Anderson RM. Patient empowerment and the traditional medical model. A case of irreconcilable differences? Diabetes Care. 1995;18(3): $412-415$.

13. Hibbard JH, Stockard J, Mahoney ER, Tusler M. Development of the patient activation measure (PAM): conceptualizing and measuring activation in patients and consumers. Health Serv Res. 2004;39(4 Pt 1): 1005-1026.

14. Sandman L, Munthe C. Shared decision-making and patient autonomy. Theor Med Bioeth. 2009;30(4):289-310.

15. King JS, Moulton B. Rethinking informed consent: the case for shared medical decision-making. Am J Law Med. 2006;32(4):429-501.

16. Wigersma L, Brabers A, Reitsma M, Jong JD. Transparantie is niet zichtbaar: Onderzoek naar opvattingen over vraagsturing in de zorg [Invisible transparency: investigating opinions regarding demand driven care]. Medisch Contact. 2011;66:2776-2778. Dutch.

17. Cegala DJ, Post DM. The impact of patients' participation on physicians' patient-centered communication. Patient Educ Couns. 2009;77(2): 202-208.

18. Cribb A, Entwistle VA. Shared decision making: trade-offs between narrower and broader conceptions. Health Expect. 2011;14(2):210-219.

19. Harrington J, Noble LM, Newman SP. Improving patients' communication with doctors: a systematic review of intervention studies. Patient Educ Couns. 2004;52(1):7-16.

20. Kinnersley P, Edwards A, Hood K, et al. Interventions before consultations to help patients address their information needs by encouraging question asking: systematic review. BMJ. 2008;337:a485.

21. Cramm JM, Nieboer AP. A longitudinal study to identify the influence of quality of chronic care delivery on productive interactions between patients and (teams of) healthcare professionals within disease management programs. BMJ Open. 2014;4(9):e005914.

22. Cramm JM, Nieboer AP. Productive patient-professional interaction improves the well-being of chronically ill patients. Qual Life Res. 2015; 24(4):897-903.

23. Cramm JM, Nieboer AP. The effects of social and physical functioning and self-management abilities on well-being among patients with cardiovascular diseases, chronic obstructive pulmonary disease, and diabetes. Applied Research in Quality of Life. 2014;9(1):113-121.

24. Rosemann T, Laux G, Szecsenyi J, Grol R. The Chronic Care Model: congruency and predictors among primary care patients with osteoarthritis. Qual Saf Health Care. 2008;17(6):442-446.

25. Brom L, Hopmans W, Pasman HR, Timmermans DR, Widdershoven GA, Onwuteaka-Philipsen BD. Congruence between patients' preferred and perceived participation in medical decision-making: a review of the literature. BMC Med Inform Decis Mak. 2014;14:25.

26. Kiesler DJ, Auerbach SM. Optimal matches of patient preferences for information, decision-making and interpersonal behavior: evidence, models and interventions. Patient Educ Couns. 2006;61(3):319-341.

27. Gittell JH. Relationships between service providers and their impact on customers. Journal of Service Research. 2002;4:299-311.

28. Gittell JH. Relational coordination: coordinating work through relationships of shared goals, shared knowledge, and mutual respect. In Kyriakidou O, Özbilgin M, editors. Relational perspectives in organizational studies: A research companion. Cheltenham (UK): Edward Elgar Publishers; 2006:74-94.
29. Gittell JH, Douglass A. Relational bureaucracy: structuring reciprocal relationships into roles. Acad Manage Rev. 2012;37(4):709-733.

30. Øvretveit J. Evidence: Does clinical coordination improve quality and save money? Volume 1: A summary review of the evidence. Health Foundation; 2011.

31. Cramm JM, Nieboer AP. The relationship between self-management abilities, quality of chronic care delivery and well-being among patients with chronic obstructive pulmonary disease in the Netherlands. Int J Chron Obstruct Pulmon Dis. 2013;8:209-214.

32. Cramm JM, Nieboer AP. Evaluatie COPD disease management programma Kennemer Lucht. Rotterdam, the Netherlands: SociaalMedische Wetenschappen; 2014.

33. Cramm JM, Jolani S, van Buuren S, Nieboer AP. Better experiences with quality of care predict well-being of patients with chronic obstructive pulmonary disease in the Netherlands. Int J Integr Care. 2015; 15:e028.

34. Glasgow RE, Wagner EH, Schaefer J, Mahoney LD, Reid RJ, Greene SM. Development and validation of the Patient Assessment of Chronic Illness Care (PACIC). Med Care. 2005;43(5):436-444.

35. Cramm JM, Strating MM, Tsiachristas A, Nieboer AP. Development and validation of a short version of the Assessment of Chronic Illness Care (ACIC) in Dutch disease management programs. Health Qual Life Outcomes. 2011;9:49.

36. Bonomi AE, Wagner EH, Glasgow RE, VonKorff M. Assessment of Chronic Illness Care (ACIC): a practical tool to measure quality improvement. Health Serv Res. 2002;37(3):791-820.

37. Gittell JH. Supervisory span, relational coordination and flight departure performance: a reassessment of post-bureaucracy theory. Organization Science. 2001;12(4):467-482.

38. Hartgerink JM, Cramm JM, Bakker TJ, van Eijsden AM, Mackenbach JP, Nieboer AP. The importance of multidisciplinary teamwork and team climate for relational coordination among teams delivering care to older patients. J Adv Nurs. 2014;70(4):791-799.

39. Hartgerink JM, Cramm JM, de Vos AJ, et al. Situational awareness, relational coordination and integrated care delivery to hospitalized elderly in the Netherlands: a comparison between hospitals. BMC Geriatr. 2014;14:3.

40. Cramm JM, Hoeijmakers M, Nieboer AP. Relational coordination between community health nurses and other professionals in delivering care to community-dwelling frail people. J Nurs Manag. 2014;22(2): $170-176$.

41. Christakis DA, Mell L, Wright JA, Davis R, Connell FA. The association between greater continuity of care and timely measles-mumps-rubella vaccination. Am J Public Health. 2000;90(6):962-965.

42. Kerse N, Buetow S, Mainous AG 3rd, Young G, Coster G, Arroll B. Physician-patient relationship and medication compliance: a primary care investigation. Ann Fam Med. 2004;2(5):455-461.

43. Buttle F, Thomas G. Questionnaire colour and mail survey response rate. J Mark Res Soc. 1997;39:625-626.
International Journal of COPD

\section{Publish your work in this journal}

The International Journal of COPD is an international, peer-reviewed journal of therapeutics and pharmacology focusing on concise rapid reporting of clinical studies and reviews in COPD. Special focus is given to the pathophysiological processes underlying the disease, intervention programs, patient focused education, and self management protocols.
Dovepress

This journal is indexed on PubMed Central, MedLine and CAS. The manuscript management system is completely online and includes a very quick and fair peer-review system, which is all easy to use. Visit http://www.dovepress.com/testimonials.php to read real quotes from published authors. 